\title{
Igreja Matriz de Nossa Senhora dos Remédios, Quevedos, RS: Uma Reflexão Patrimonial
}

\author{
Iglesia Matriz de Nuestra Señora De Los Remedios, Quevedos, RS: Una \\ Reflexión Patrimonial
}

\author{
Church of Our Lady of Remedies, Quevedos, RS: A Reflection about \\ Heritage
}

\author{
Ma. Natália Lampert Batista ${ }^{1}$ \\ Dra. Elsbeth Léia Spode Becker ${ }^{2}$ \\ Lic. Leandro da Silva Roubuste ${ }^{3}$
}

\begin{abstract}
Resumo
Interpretar e valorar os elementos de uma paisagem perpassa pela capacidade que tem o receptor de organizar mentalmente sua percepção do local, bem como com o seu conhecimento sobre a história dos elementos que a constituem. No município de Quevedos, observa-se uma fraca percepção da necessidade de preservar o passado e as memórias coletivas do lugar. Partindo dessas premissas, o presente trabalho objetiva realizar uma leitura, sob o enfoque patrimonial, frente à antiga Igreja Matriz de Nossa Senhora dos Remédios, que foi destruída para dar espaço a uma nova Igreja, mais moderna e mais ampla. A metodologia foi embasada na revisão bibliográfica e na perspectiva da pesquisa qualitativa, de caráter empírico por meio da observação direta e participante, por registro visual, fotográfico e de depoimentos. Constatou-se que, mesmo com a existência de uma rica memória individual e coletiva em Quevedos, não há uma valoração dos elementos constitutivos para paisagem local.
\end{abstract}

Palavras-Chave: Elemento da Paisagem, Patrimônio Histórico, Pertencimento, Valorização do Novo.

\section{Resumen}

Interpretar y valorar los elementos de un paisaje pasa por la capacidad que tiene el receptor de organizar mentalmente su percepción del local, así como con su conocimiento sobre la historia de los elementos que la constituyen. En el municipio de Quevedos, se percibe una débil percepción de la necesidad de preservar el pasado y las memorias colectivas del sitio. Partiendo de esas premisas, el presente trabajo realiza una lectura bajo el enfoque patrimonial frente a la antigua Iglesia Matriz de Nuestra Señora de los Remedios, que fue destruida para dar espacio a una nueva Iglesia, más moderna y más amplia. La metodología fue basada en la revisión bibliográfica y en la perspectiva de la investigación cualitativa, de carácter empírico por medio de la observación directa y participante, por registro visual, fotográfico y de testimonios. Se constató que aún con la existencia de una rica memoria individual y colectiva de Quevedos, no hay una valoración de los elementos constitutivos del paisaje local.

Palabras claves: Elemento del Paisaje, Patrimonio Histórico, Pertenencia, Valorización del Nuevo.

\footnotetext{
${ }^{1}$ Mestra e doutoranda em Geografia; Universidade Federal de Santa Maria; Santa Maria, Rio Grande do Sul, Brasil; natilbatista3@gmail.com.

${ }^{2}$ Doutora em Agronomia; Centro Universitário Franciscano; Santa Maria, Rio Grande do Sul, Brasil; elsbeth.geo@gmail.com.

${ }^{3}$ Licenciado em Filosofia; Faculdade SOBRESP; Santa Maria, Rio Grande do Sul, Brasil; leandroroubuste@gmail.com.
} 
Abstract

Interpret and value the elements of a landscape permeates the ability of the receiver organize mentally their perception of the local, as well as their knowledge about the history of the elements that constitute it. In the municipality of Quevedos, one sees a poor perception of the need to preserve the past and collective memories of the place. Because of that, this paper aims do one reading about the old Church of Our Lady of Remedies, which was destroyed to make room for a new church, more modern and wider. The methodology was based on the literature review and the perspective of qualitative and empirical research, through direct and participant observation by visual record, photographic and testimonials. It was found that even with the existence of a rich individual and collective memory of Quevedos there is not a valuation of the constituent elements of the local landscape.

Keywords: Landscape Element, History Heritage, Belonging, New appreciation.

\section{Introdução}

O desejo do ser humano de conhecer e de interpretar a paisagem urbana está estreitamente atrelado à dimensão Cultural da Geografia. É nítida a abordagem da subjetividade neste ato de conhecimento, o que de acordo com a vivência de cada indivíduo, transforma um espaço banal/cotidiano em lugar significativo e experiencial.

A paisagem passa a ser entendida e valorada por meio das vivências do indivíduo e o estudo lugar se torna essencial ao desenvolvimento das noções de pertencimento e de identidade. As cidades, com suas praças, seus prédios, suas ruas, suas casas, contém a vida humana em sociedade. É o espaço das relações e, por isso, também, o espaço das memórias. Alguns locais específicos, como a Igreja Matriz de Nossa Senhora dos Remédios, adquirem importância ou são marcados, geralmente, pelos acontecimentos do passado e por novas interações desencadeadas pelas relações sociais.

A memória nesses lugares é "a imagem viva de tempos passados ou presentes. Os bens, que constituem os elementos formadores do patrimônio, são ícones repositórios da memória, permitindo que o passado interaja com o presente, transmitindo conhecimento e formando a identidade de um povo" (GHIRARDELLO; SPISSO, 2008, p. 13). Espaços marcados pelas memórias coletivas e individuais de uma população são essenciais à formação de raízes identitárias e a preservação da história local.

A preservação de bens patrimoniais deve ter por finalidade conservar traços da vida comum, quotidiana, e mostrar como vivia a sociedade em determinada época, pois o que tende a ser conservado sempre será o objeto considerado valioso, seja pelo valor do material de que é composto, seja por uma herança histórica ligada a uma personalidade ilustre e por isso mesmo dominadora. A conservação de bens patrimoniais deve ter por objeto edificações que tenham um significado coletivo para determinada comunidade, pois se perpetua a memória de uma sociedade preservando-se os espaços utilizados por ela na construção de sua história (TOMAZ, 2010, p. 5). 
RELACult - Revista Latino-Americana de Estudos em Cultura e Sociedade

Revista Latinoamericana de Estudios en Cultura y Sociedad | Latin American Journal of Studies in Culture and Society

V. 02, nº 03, set-dez., 2016, p. 33-43 | periodicos.claec.org e-ISSN Atual: 2525-7870 | e-ISSN Anterior: 2447-018X

Neste contexto, a Igreja Matriz mencionada, construída na década de 1960, foi um ponto significativo na memória coletiva do município de Quevedos (figura 1). Porém, devido à falta de percepção sobre sua dimensão cultural/patrimonial foi destruída para dar lugar a uma nova Igreja, mais moderna e mais ampla, fato característico da sociedade do espetáculo, que vê apenas o jovem e o grandioso como digno de admiração e de desejo (BAUMAN, 2001).

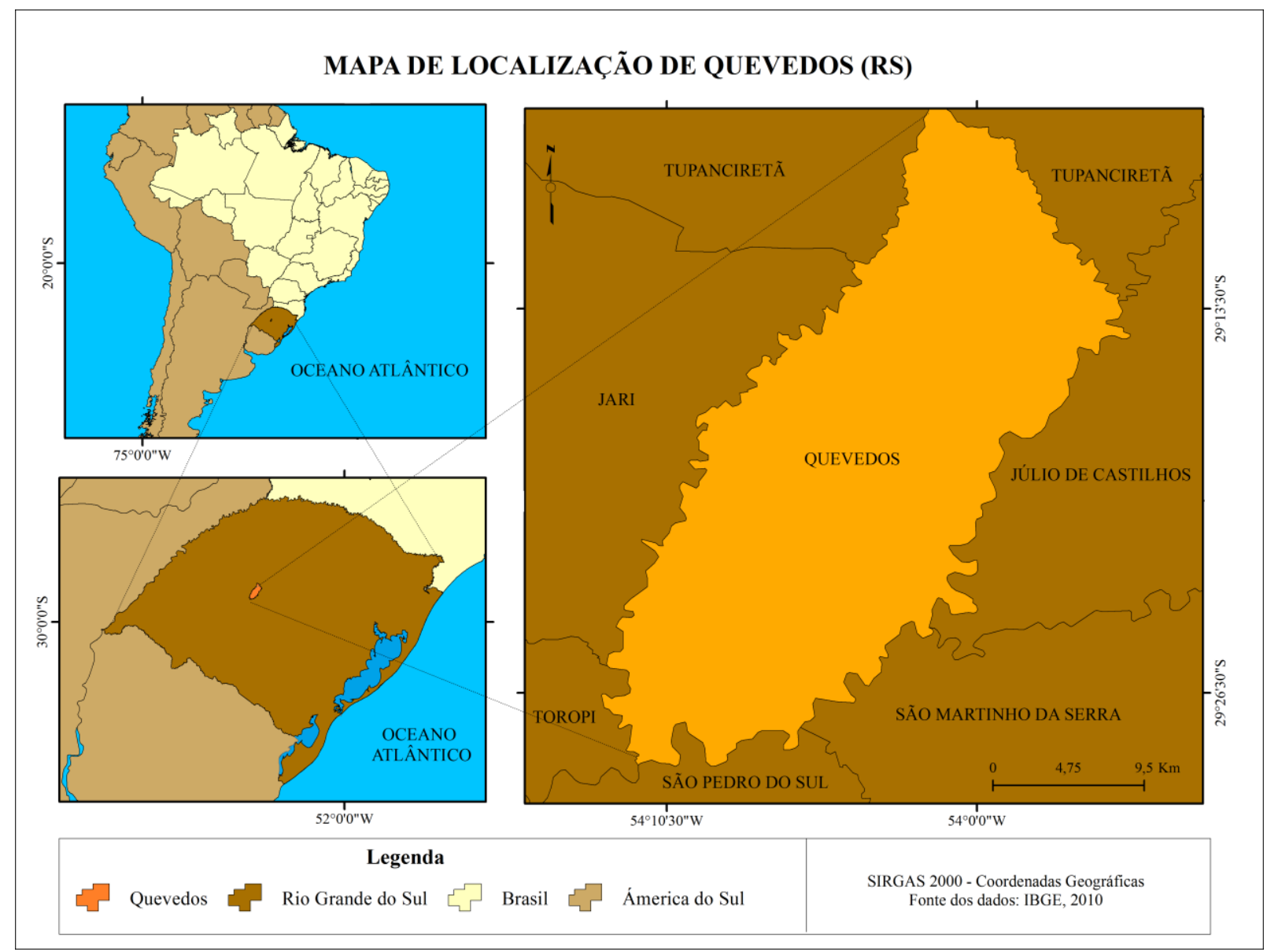

Figura 1: Mapa de localização do município de Quevedos, RS.

Fonte: Arquivo Pessoal dos Autores, 2016.

$\mathrm{O}$ fato relatado evidencia a necessidade de estudos que visem promover e gerar atratividade ao conhecimento e a preservação da histórica local, não apenas para aqueles que ali vivem, mas também para os visitantes. Partindo das ideias apresentadas, o presente trabalho objetiva realizar uma leitura, sob o enfoque patrimonial, frente à antiga Igreja Matriz de Nossa Senhora dos Remédios. 


\section{Igreja Matriz Nossa Senhora dos Remédios: um marco na paisagem quevedense}

Compreender e valorar os elementos da paisagem local permite o resgate da memória coletiva dos lugares e possibilita o desenvolvimento das noções de pertencimento e de identidade de um local. Em relação à compreensão do estudo da paisagem, Claval (1999, p. 420) afirma que "[...] não há compreensão possível das formas de organização do espaço contemporâneo e das tensões que lhes afetam sem levar em consideração os dinamismos culturais. Eles explicam a nova atenção dedicada à preservação das lembranças do passado e a conservação das paisagens". Assim, Claval não só atribui ao homem à responsabilidade de transformar a paisagem como destaca que distintos grupos culturais são capazes de provocar transformações diferenciadas nela, criando uma preocupação maior com os sistemas culturais do que com os próprios elementos físicos da paisagem.

Para compreender a valorização dos elementos da paisagem enquanto patrimônio pode-se destacar o conceito de Ghirardello e Spisso (2008, p. 13-14) que o definem como "[...] o conjunto de bens, de natureza material e/ou imaterial, que guarda em si referências à identidade, a ação e a memória dos diferentes grupos sociais. É um elemento importante para o desenvolvimento sustentado, a promoção do bem-estar social, a participação e a cidadania”.

Um segundo conceito é apresentado por Tomaz (2010, p. 3) ao afirmar que:

[...] o estudo do patrimônio cultural promove a valorização e consagração daquilo que é comum a determinado grupo social no tempo e no espaço. Esse patrimônio compreende três grandes categorias: a primeira engloba os elementos pertencentes à natureza, ao meio ambiente; a segunda refere-se ao conhecimento, às técnicas, ao saber e ao saber-fazer; e a terceira trata mais objetivamente do patrimônio histórico, que reúne em si toda a sorte de coisas, artefatos e construções resultantes da relação entre o homem e o meio ambiente e do saber-fazer humano, ou seja, tudo aquilo que é produzido pelo homem ao transformar os elementos da natureza, adequando-os ao seu bem-estar.

Assim, percebe-se que a Igreja Matriz de Nossa Senhora dos Remédios era comtemplada na dimensão patrimonial, porque foi um marco na memória local, reunindo referências à identidade e às ações dos grupos sociais locais. Nesta perspectiva, Nigro (2003, p.167) destaca que

A noção de patrimônio se fortificou, no século XIX, buscando legitimar a possibilidade de posse pública de bens culturais que, em nome da coletividade, passaram a ser assegurados pelo Estado. Desde então, englobando bem culturais de valor inquestionável, o patrimônio se firmou onde melhor sobreviveu a ideologia dos setores oligárquicos. Além disso, só experts passam a ter competência de lidar com as questões de preservação e zelar pelo patrimônio. (...) $\mathrm{O}$ processo de democratização do patrimônio advém do distanciamento muito 
RELACult - Revista Latino-Americana de Estudos em Cultura e Sociedade

Revista Latinoamericana de Estudios en Cultura y Sociedad | Latin American Journal of Studies in Culture and Society

V. 02, no 03, set-dez., 2016, p. 33-43 | periodicos.claec.org e-ISSN Atual: 2525-7870 | e-ISSN Anterior: 2447-018X

grande envolvendo as instituições de preservação e os sujeitos sociais para as quais, teoricamente, suas atividades deveriam estar dirigidas: os habitantes.

Com base no exposto, a Igreja Matriz de Nossa Senhora dos Remédios (figuras 2a e 2b) foi um patrimônio cultural do município de Quevedos que acabou sendo destruído para dar espaço a uma nova estrutura com padrões arquitetônicos contemporâneos.
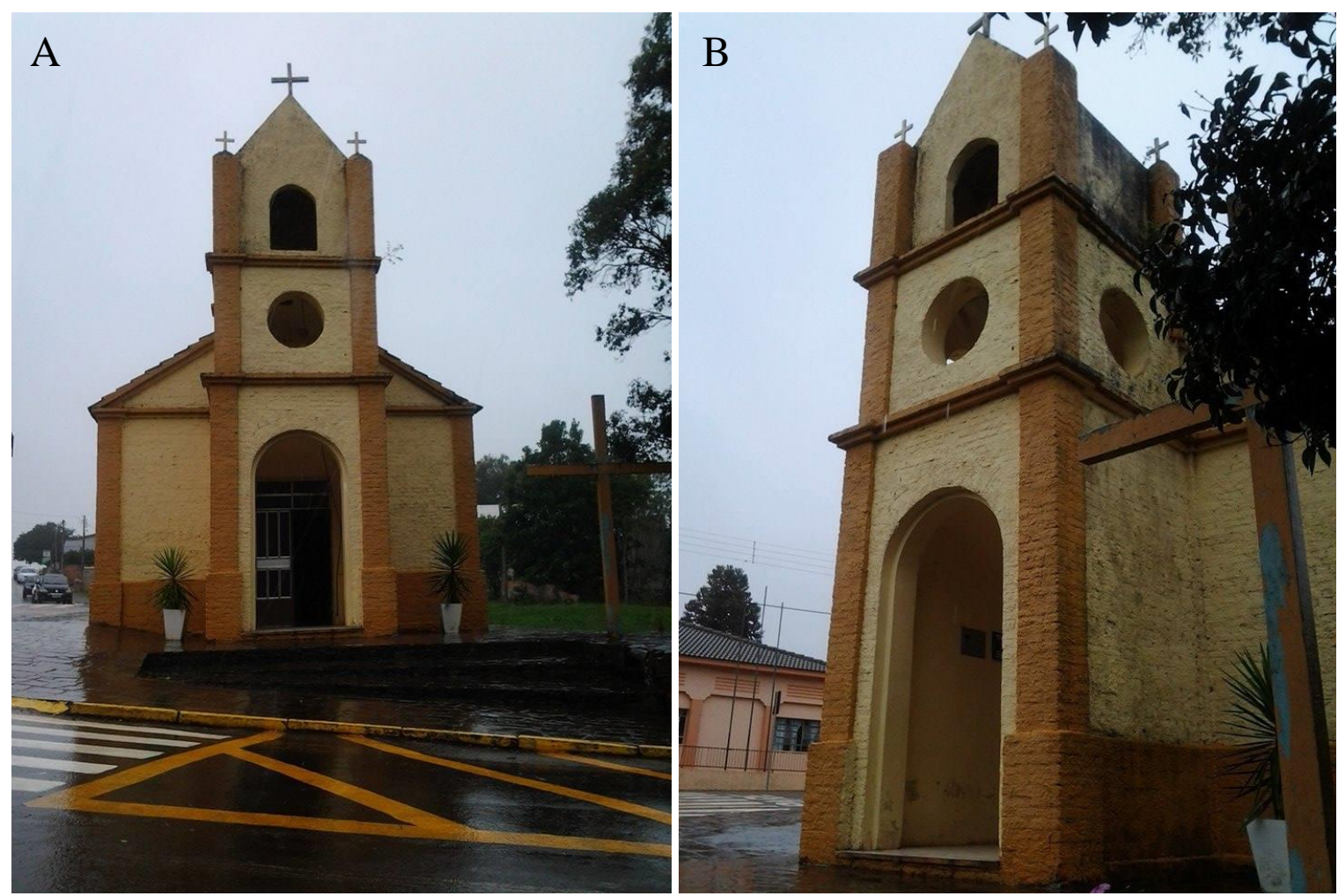

Figura 2: a e b) Fachada da Igreja Matriz de Nossa Senhora dos Remédios (Quevedos, RS).

Fonte: Arquivo Pessoal, 2015.

"A Igreja de Quevedos possuía estilo Neoclássico, onde na fachada, eram visíveis dois frontões triangulares que denotavam Ordem, Equilíbrio e Simetria, características do classicismo greco-romano-renascentista. Na fachada um módulo mais avançado se destacava em direção ao espaço urbanístico, constituindo a torre campanária. Nela era possível observar um grande arco pleno que abarca toda a entrada da igreja. No espaço central, um óculo e, mais acima, inserido num frontão triangular, outro arco pleno, menor. Este módulo estava dividido em três partes com saliências que se destacavam devido à cor mais escura, a qual contorna toda a construção e estava encimado por um frontão triangular onde foram colocadas três cruzes gregas. Na lateral da torre eram visíveis, ainda, duas outras pequenas cruzes gregas 
RELACult - Revista Latino-Americana de Estudos em Cultura e Sociedade

na parte posterior e um óculo na lateral. O umbral da porta fazia um jogo de luz e sombra, pois se destaca com um aspecto nervurado. Toda a construção era de tijolos e recebeu cor ocre e detalhes salientes em marrom. Seu interior (figuras $3 a$ e $3 b$ ) era muito singelo tendo a direita do altar, a imagem de São José e a esquerda a imagem de Nossa Senhora do Carmo. O altar é constituído de uma mesa simples e acima dela, o Sacrário e na parede do fundo, um pequeno crucifixo" (Descrição realizada pela Prof ${ }^{a}$. Dr ${ }^{a}$. Edir Bisognin a pedido dos autores).
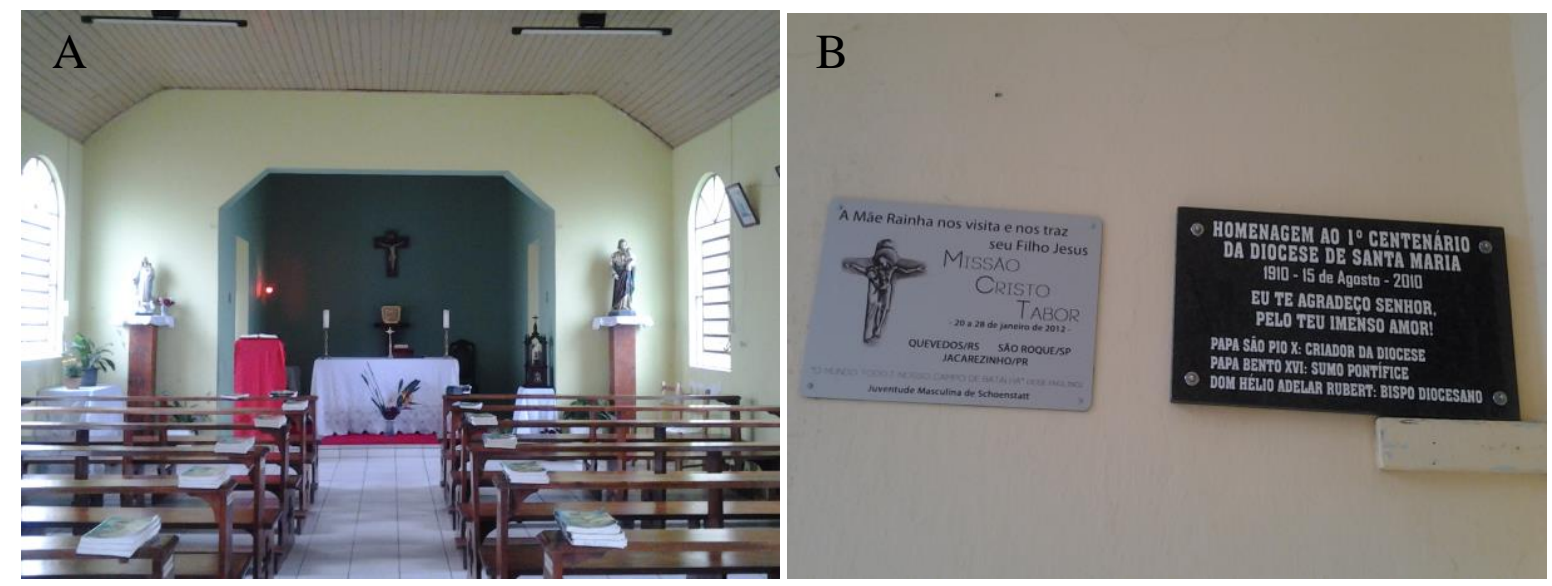

Figura 3: a e b) Interior da Igreja Matriz de Nossa Senhora dos Remédios (Quevedos, RS).

Fonte: Arquivo Pessoal, 2015.

Em outubro de 2015, colocou-se em prática um projeto que destruir a antiga Igreja Matriz e erguer uma nova. Apesar de polêmico entre os moradores, teve prosseguimento, fazendo emergir os questionamentos: quais são os patrimônios históricos de Quevedos? E porque preservar o patrimônio histórico do município?

A seguir destacam-se alguns depoimentos sobre o fato e evidenciam-se as percepções predominantes dos moradores o lugar:

Depoimento 1: “Ontem foi um dia pra ficar na memória do povo quevedense, foi o dia do desmanche da nossa antiga Igreja Matriz, que já não estava mais em condições de uso como podemos ver nas fotos estava sem condições de reforma além de ter pouco espaço, e como ela não é um patrimônio histórico pois... Patrimônio histórico é a nossa antiga Igrejinha que continua e sempre vai continuar de pé. As missas continuarão sendo rezadas na nossa antiga Igrejinha como já tem sido feito, e a partir de agora a nossa fé Católica continua com mais força ainda contando com o apoio de muitos colaboradores que estão se empenhando de corpo e alma para que nossa cidade tenha uma nova Matriz onde possamos 
RELACult - Revista Latino-Americana de Estudos em Cultura e Sociedade e-ISSN Atual: 2525-7870|e-ISSN Anterior: 2447-018X

acolher nossos fiéis com um templo lindo como vai ficar e muito mais acolhedor... Todos nós a equipe de trabalho estamos muito felizes com esse acontecimento e não vemos a hora de ver a nova Matriz de pé e temos certeza que Nossa Senhora dos Remédios ficará muito feliz com sua nova casa. Agradecemos toda a equipe que ajudou nesse dia para que tudo ocorresse bem" (Depoimento de um participante do conselho de construção da nova Igreja em uma rede social).

O depoimento destaca, em especial, o tamanho da Igreja que não comportava muitos fiéis, porém, existiram dois projetos alternativos, um que visava conservar a fachada da antiga Igreja e ampliá-la e outro de construir a nova Igreja em outro terreno. Porém, ambos foram rejeitados pela comunidade que, por motivo apresentados no depoimento 2 , optou por destruir o templo existente. Já a menção a "nossa antiga Igrejinha" se refere à primeira Igreja Matriz do município (figura 4) que foi construída em 1820 pela família dos primeiros moradores do lugar. Todavia, essa Igreja não é utilizada pela população e vem apresentando sua dimensão patrimonial seriamente comprometida nos últimos anos. Em conjunto com o "Casarão", primeira residência do município, vem sendo encoberta por construções e perdendo todo o destaque na paisagem. Hoje, sua fachada se encontra escondida por casas que avançam compulsivamente sobre a pequena Igreja. Logo, assim como a Igreja Matriz de Nossa Senhora dos Remédios, a Igrejinha não é valorizada e respeitada como patrimônio histórico do município de Quevedos, o que demostra uma frágil noção sobre o real significado da discussão patrimonial no lugar.

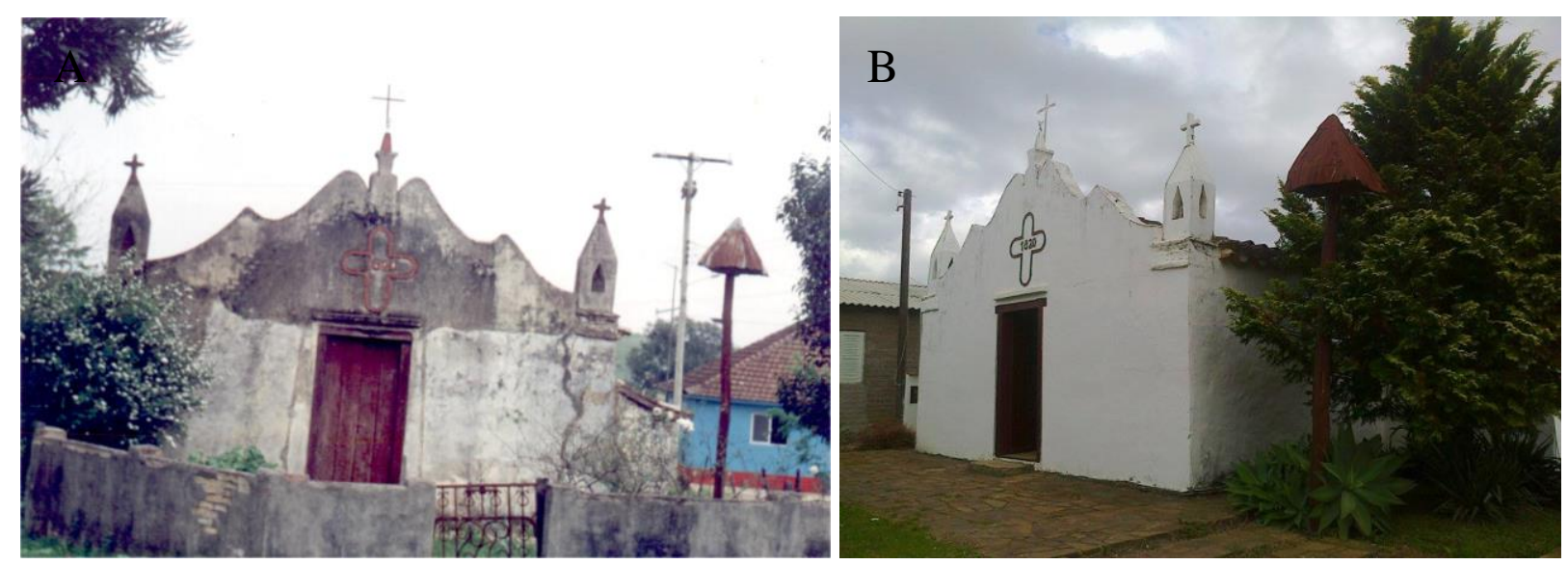

Figura 4 - Primeira Igreja de Nossa Senhora dos Remédios: a) Década de 1990 e b) 2015.

Fonte: a) Câmara Municipal dos Vereadores; b) Autores, 2015. 
Depoimento 2: "As Missas e todas as atividades continuam realizadas na Igrejinha até que a nova Igreja Matriz seja construída. A vida da Igreja Católica de Quevedos permanece a mesma. Uma nova Igreja ampla, de grande qualidade arquitetônica será um marco para a cidade que merece ter uma Igreja Matriz à altura dos demais municípios. A antiga Igreja agora desfeita não possuia nenhum elemento histórico cultural que justificasse sua manutenção. Além disso, sua estrutura necessitaria de uma reforma completa que se tornaria inviável e ela continuaria pequena, apertada e sem o espaço necessário que uma Igreja Matriz necessita. A decisão do pároco, do conselho e da equipe de construtores nunca foi desmerecer a história, mas ao contrário oferecer à história do município uma Igreja que com certeza o caracterizará por mais de um século. Quanto à possibilidade de construir em outro lugar, isso também foi avaliada. No entanto não surgiu nenhuma "alma" generosa que se dispusesse a doar um amplo terreno nas ruas centrais da cidade e a paróquia por si só não tinha condições de adquiri-lo. Então, resta-nos trabalhar com o espaço que temos. É importante saber que muitos estão colaborando consideravelmente com essa obra não só financeiramente, mas fisicamente, dedicando seu tempo, deixando seus trabalhos e suas preocupações para se doarem a si mesmos. Agora é importante o apoio de todos para logo nos alegrarmos com nossa nova Igreja. Qualquer dúvida pode ser esclarecida na secretaria da paróquia ou com o pessoal do conselho e da equipe de construção" (Depoimento de participante do conselho de construção da nova Igreja em uma rede social).

O segundo depoimento se caracteriza pela "conceituação" do que não é um patrimônio histórico, porém, é importante destacar que para ser considerado patrimônio não é necessário elementos luxuosos e exuberantes, o que deve predominar é a existência de memória significativas e da identidade da população local. Segundo Ghirardello e Spisso (2008, p. 17) “[...] muitos imóveis modestos possuem técnicas construtivas interessantes, originalidade, expressam hábitos ou outro valor, como as casas de tábua trazidas pela ferrovia, as obras de taipa de mão ou taipa de pilão, ou as manufaturas e fábricas, por exemplo". A Igreja Matriz de Nossa Senhora dos Remédios, traz a história de seus moradores, as vivências de toda uma geração de esteve altamente vinculada a esse espaço, como pode ser observado no depoimento 3.

Além disso, um bem cultural não se caracteriza por ser "Uma nova Igreja ampla, de grande qualidade arquitetônica [que] será um marco para a cidade que merece ter uma Igreja Matriz à altura dos demais municípios". Uma pequena capela, construída e vivida pela comunidade, tem muito mais valor patrimonial e possivelmente arquitetônico que uma imensa Igreja construída para atender visões extremas, onde o que realmente importa é a aparência e 
RELACult - Revista Latino-Americana de Estudos em Cultura e Sociedade e-ISSN Atual: 2525-7870 | e-ISSN Anterior: 2447-018X

não a essência do lugar. Não se pode "oferecer à história do município uma Igreja que com certeza o caracterizará por mais de um século" sem que essa seja apropriada pelos moradores e tida como uma referência em suas memórias.

Depoimento 3: "Mesmo que vão contruir um Igreja nova... Fico triste, triste mesmo... Embora que entendo dessa decisão, devido a falta de espaço... E quando coloco que não gostei da ideia da demolição do prédio da Igreja... Ver e pensar que tudo que já passou lá... Batizados, primeira comunhão, crisma, casamentos... Milhares celebrações.... Uma VIDA! Não terá mais como dizer "meu filho! Aqui você foi batizado...". Para mim, muita gente também acredita, que essa Igreja (pequena ou não) que foi demolida faz parte a história de Quevedos e sua população... O que é belo não deve ser destruído... Poderiam construir uma Igreja nova em outro lugar "(Depoimento de um morador da cidade em uma rede social).

Como se pode observar, a justificativa de reconstrução da nova Igreja é pautada na justificativa de "não ser patrimônio histórico", porém isso é evidentemente desmistificado no depoimento 3 que evidencia todos os acontecimentos no prédio e demostra um forte vínculo afetivo com o lugar. Esse sentimento permeou grande parte da comunidade, especialmente, no dia de sua demolição (figuras 5a e 5b). Desse modo, "É possível observar que muitas vezes, por motivos meramente comerciais, prefere-se demolir o velho, por considerá-lo impróprio, e substituí-lo pelo novo, mais contemporâneo e funcional, mais adequado às necessidades da vida moderna, sempre exigente em suas demandas” (TOMAZ, 2010, p. 4).
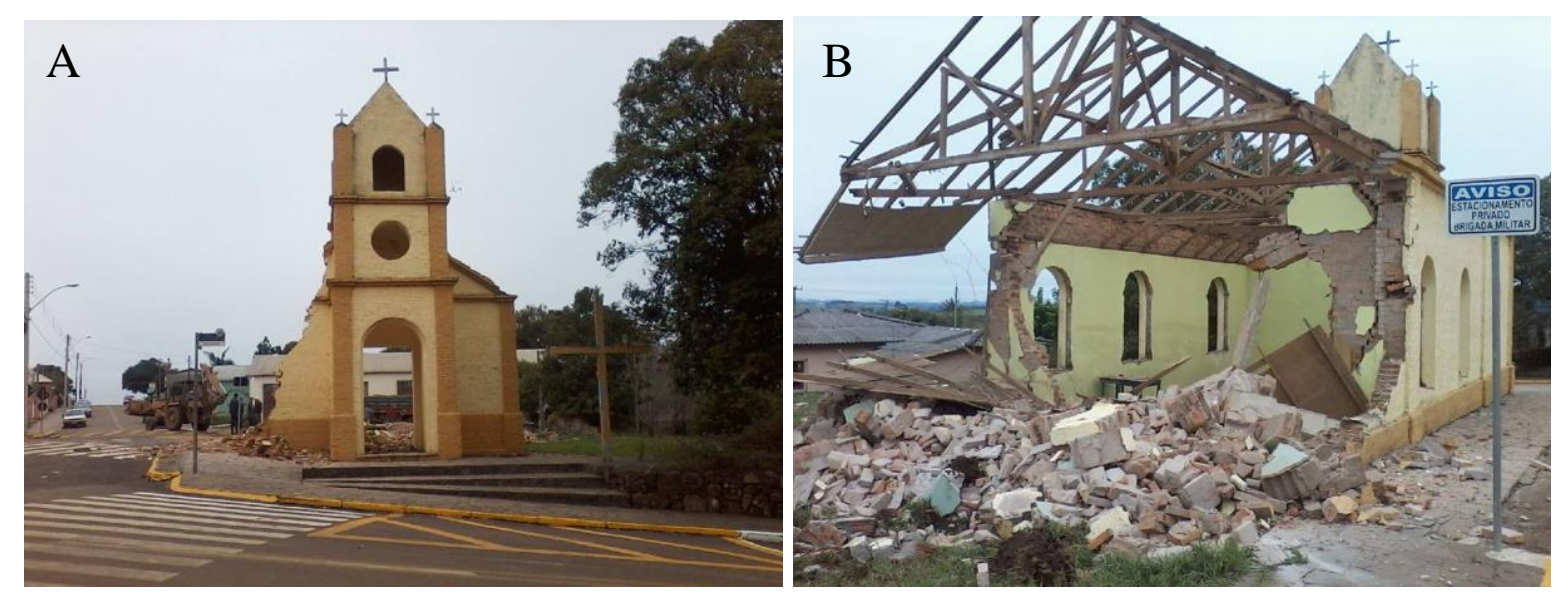

Figura 5: a e b) Desconstrução da Igreja Matriz de Nossa Senhora dos Remédios (Quevedos, RS).

Fonte: Material divulgado pela Secretária da Paróquia, 2015. 
RELACult - Revista Latino-Americana de Estudos em Cultura e Sociedade

Revista Latinoamericana de Estudios en Cultura y Sociedad | Latin American Journal of Studies in Culture and Society

V. 02, no 03, set-dez., 2016, p. 33-43 | periodicos.claec.org e-ISSN Atual: 2525-7870 | e-ISSN Anterior: 2447-018X

Partindo das visões apresentadas e da evidente necessidade de pensar e de preservar o patrimônio histórico de Quevedos, torna-se extremamente necessário discutir o que é realmente constitutivo da memória de um lugar, porque

Cada indivíduo é parte de um todo - da sociedade e do ambiente onde vive - e constrói, com os demais, a história dessa sociedade, legando às gerações futuras, por meio dos produtos criados e das intervenções no ambiente, registros capazes de propiciar a compreensão da história humana pelas gerações futuras. A destruição dos bens herdados das gerações passadas acarreta o rompimento da corrente do conhecimento, levando-nos a repetir incessantemente experiências já vividas. Atualmente, a importância da preservação ganha novo foco, decorrente da necessária consciência de diminuirmos o impacto sobre o ambiente, provocado pela produção de bens. A preservação e o reuso de edifícios e objetos contribuem para a redução de energia e matéria-prima necessárias para a produção de novos. [Devendo ser preservados] todos os bens de natureza material e imaterial, de interesse cultural ou ambiental, que possuam significado histórico, cultural ou sentimental, e que sejam capazes, no presente ou no futuro, de contribuir para a compreensão da identidade cultural da sociedade que o produziu (GHIRARDELLO; SPISSO, 2008, p. 15).

Portanto, a Igreja Matriz de Nossa Senhora dos Remédios era um patrimônio histórico do município de Quevedos e como tal deveria ter sido preservado como forma de valorização da memória, da cultura e da identidade do lugar. Sua desvalorização, por referenciais fluídos e contemporâneos, desconstruiu uma paisagem de décadas e perdeu uma significativa parte da memória coletiva do município de Quevedos.

\section{Conclusões}

Com base nos referenciais de Geografia Cultural e nos depoimentos apresentados se observa a necessidade de discutir a questão patrimonial do município de Quevedos, deixando claro que todo o prédio com uma forte influência nas memórias individuais e coletivas de uma comunidade, mesmo que não tombado pela lei de patrimônio, pode ser caracterizado como tal. Além disso, evidencia-se a necessidade de promover ações que levem os moradores do município de Quevedos a conhecer sua história e, consequentemente, desenvolver sentimentos de pertença e de identidade, passando a preservar a sua história e seus elementos paisagísticos.

\section{Referências}

BAUMAN, Z. Modernidade líquida. Rio de Janeiro: Jorge Zahar, 2001.

CLAVAL, P. A geografia cultural. Florianópolis: UFSC, 1999. 

e-ISSN Atual: 2525-7870 | e-ISSN Anterior: 2447-018X

GHIRARDELLO, N.; SPISSO, B. (Orgs.) Patrimônio histórico: como e por que preservar. Bauru, SP: Canal 6, 2008. Disponível em:

http://www.creasp.org.br/arquivos/publicacoes/patrimonio_historico.pdf. Acesso em setembro de 2016.

NIGRO, C. Território do patrimônio: tombamentos e mobilizações sociais. In: CARLOS, A. F. A.; LEMOS, A. I. G. (Org.). Dilemas Urbanos: novas abordagens sobre a cidade. São Paulo: Contexto, 2003.

TOMAZ, P. C. A história do Patrimônio Cultural no Brasil. In: Fênix-Revista de História e Estudos Culturais. Maio/ Junho/ Julho/ Agosto de 2010 Vol. 7 Ano VII, no 2. p: 1 -12. Disponível em:

http://www.revistafenix.pro.br/PDF23/ARTIGO_8_PAULO_CESAR_TOMAZ_FENIX_MA IO_AGOSTO_2010.pdf. Acesso em setembro de 2016. 